\title{
Anthocyanin Extract of Purple Corn Improves Hyperglycemia and Insulin Resistance of Rats Fed High Fat and Fructose Diet via GLP1 and GLP1R Mechanism
}

\author{
Ichda Chayati $^{1,2, *}$, Sunarti ${ }^{3}$, Yustinus Marsono ${ }^{4}$, Mary Astuti ${ }^{4}$ \\ ${ }^{1}$ Department of Food and Fashion Engineering Education, Faculty of Engineering, \\ Yogyakarta State University, Yogyakarta, Indonesia 55281 \\ ${ }^{2}$ Doctoral Program of Food Science, Department of Food and Agricultural Product Technology, \\ Gadjah Mada University, Yogyakarta, Indonesia 55281 \\ ${ }^{3}$ Department of Biochemistry, Faculty of Medicine, Public Health and Nursing, \\ Gadjah Mada University, Yogyakarta, Indonesia 55281 \\ ${ }^{4}$ Department of Food and Agricultural Product Technology, Faculty of Agricultural Technology, \\ Gadjah Mada University, Yogyakarta, Indonesia 55281 \\ *Corresponding author: ichda_chayati@uny.ac.id
}

Received January 10, 2019; Revised March 08, 2019; Accepted April 10, 2019

\begin{abstract}
Hyperglycemia and insulin resistance are caused by high fat, fructose, or fat and fructose diet. The aim of this study was to investigate the effect of anthocyanin extract of purple corn (AEPC) on insulin resistance of rats fed high fat and fructose diet (HFFD). Insulin resistance was induced by feeding HFFD for 4 weeks and Wistar male rats were orally supplemented with the following treatments for the next six weeks: pioglitazone $1.35 \mathrm{mg} \mathrm{kg}^{-1}$ body weight (bw) as a positive control group (PC), AEPC $6 \mathrm{mg} \mathrm{kg}^{-1}$ bw (LA), AEPC $12.5 \mathrm{mg} \mathrm{kg}^{-1}$ bw (MA), and AEPC $25 \mathrm{mg} \mathrm{kg}^{-1}$ bw (HA), or no treatment as a negative control group (NC). A normal control group was fed a normal diet (NLC) for along 10 weeks. Insulin resistance was indicated by Homeostasis Model Assessments for Insulin Resistance (HOMA-IR) scores. The results showed that HFFD feeding increased HOMA-IR score and blood glucose levels, and decreased levels of plasma glucagon-like peptide 1 (GLP1) and pancreatic glucagon-like peptide 1 receptor (GLP1R). Administration of AEPC reduced HOMA-IR scores and blood glucose levels, increased HOMA- $\beta$ and HOMA-IS scores, plasma GLP1 and pancreatic GLP1R levels, and improved pancreatic morphology. Our finding suggests that AEPC $12.5 \mathrm{mg} \mathrm{kg}^{-1}$ bw gave the best conditions to improve insulin resistance as well as standard drug administration pioglitazone $1.35 \mathrm{mg} \mathrm{kg}^{-1} \mathrm{bw}$ via GLP1 and GLP1R mechanism.
\end{abstract}

Keywords: anthocyanin, purple corn, hyperglycemia, insulin resistance, GLP1, GLP1R

Cite This Article: Ichda Chayati, Sunarti, Yustinus Marsono, and Mary Astuti, "Anthocyanin Extract of Purple Corn Improves Hyperglycemia and Insulin Resistance of Rats Fed High Fat and Fructose Diet via GLP1 and GLP1R Mechanism." Journal of Food and Nutrition Research, vol. 7, no. 4 (2019): 303-310. doi: $10.12691 /$ jfnr-7-4-7.

\section{Introduction}

The global prevalence of diabetes was estimated to be 9\% in 2014 [1]. According to Basic Health Research 2018, in Indonesia, prevalence of diabetes in 2018 was $10.9 \%$ of over 15 year-old population based on diabetes diagnose criteria by Indonesian Endocrinology Association 2015 [2]. One of the most responsible cause of diabetes is insulin resistance [3]. High-fat diets cause obesity-induced metabolic syndrome [4], oxidative stress [5,6,7], and trigger insulin resistance $[8,9,10]$. Moreover, overconsumption of fructose plays a role in insulin resistance [11,12], obesity [13], and oxidative stress [14,15]. Therefore, treatment with antioxidants can prevent hyperglycemia and insulin resistance caused by high-fat and high-fructose diets
(HFFD). One type of antioxidant is anthocyanin which is a group of flavonoid compounds that give the colors orange, red, purple, and bright blue, that is found naturally in fruits and vegetables. One source of anthocyanin is purple corn [16]. In Indonesia, purple corn is being cultivated and one of its kind is dark purple corn from Malang, East Java, Indonesia.

Several studies on purple corn anthocyanin extract demonstrate the ability to inhibit prostate carcinogenesis [17], improve oxidative stress conditions [18], inhibit carcinogenesis of mammas [19], inhibit colon cancer [16], and improve conditions in diabetic nephropathy [20]. However, there has been no study of anthocyanin extract of purple corn (AEPC) on hyperglycemia and insulin resistance in HFFD rats, therefore this investigation was important. Several studies resulted that anthocyanin acted as antihyperglicemia by delaying carbohydrate digestion 
and inhibiting the rate of glucose absorption across the intestine [21-25]. This research focuses on the mechanism of antihyperglycemia and insulin resistance amelioration via GLP1 and GLP1R levels improvement.

\section{Materials and Methods}

\subsection{Extract Preparation}

Purple corn (Zea mays) seed kindly given by Dr. Arifin Noor Sugiharto was cultivated in Gadjah Mada University land. After 3 months, it was cropped and sun-dried (before $12 \mathrm{pm}$ ) to a water content of ca. 12\%. Furthermore, it was ground and sieved using a 60-mesh size screen. The unsieved part powder was then extracted using ethanol-3\% citric acid $(1: 10, \mathrm{w} / \mathrm{v})$, mascerated at $1000 \mathrm{rpm}$ using magnetic stirrer at ambient temperature for 3 hours. The extract was centrifuged at $3000 \mathrm{rpm}$ at ambient temperature for 20 minutes. The supernatant was evaporated to dryness at $40^{\circ} \mathrm{C}$ with rotary evaporator Buchi R-3000 (Buchi Labortechnic AG, Flawil, Switzerland). The thick extract was sealed and stored in dark condition at $-20^{\circ} \mathrm{C}$ until use. The characteristic of AEPC was $2.55 \mathrm{mg} / \mathrm{ml}$ of total anthocyanin content and $0.229 \mu$ mol Trolox Equivalent (TE) $\mathrm{mL}^{-1}$ of total antioxidant capacity. Anthocyanin components of AEPC were cyanidin-3-glucoside $27.8 \mathrm{ppm}$ and peonidin-3-glucoside $10.4 \mathrm{ppm}$ (data not published).

\subsection{Animals}

Twenty four male Wistar rats age 2 months were purchased from The National Agency of Drug and Food Control (Yogyakarta, Indonesia). The animals were maintained at $21-25^{\circ} \mathrm{C}$ and $50-60 \%$ of humidity and kept on a $12 \mathrm{~h}$ light- $12 \mathrm{~h}$ dark cycle with free access to food and water. The research protocol was approved by The Committee of Ethical Clearance for Pre-clinical Research of The Integrated Laboratory of Research and Testing, Gadjah Mada University, Yogyakarta, Indonesia Ref: 441a/KEC-LPPT/III/2016.

Table 1. Composition and energy values of ND and HFFD

\begin{tabular}{lcccc}
\hline \multirow{2}{*}{ Ingredient } & \multicolumn{2}{c}{$\mathrm{ND}$} & \multicolumn{2}{c}{ HFFD } \\
\cline { 2 - 5 } & $\mathrm{g}$ & $\mathrm{kcal}$ & $\mathrm{g}$ & Kcal \\
\hline Cornstarch & 62 & 248 & 47.5 & 190 \\
Sucrose & 10 & 40 & - & - \\
Fructose & - & - & 10 & 40 \\
Casein & 14 & 56 & 14 & 56 \\
Soybean oil & 4 & 36 & 3 & 27 \\
Beef tallow & - & - & 15 & 135 \\
Cholesterol & - & - & 0.5 & - \\
Alphacel & 5 & - & 5 & - \\
AIN-93-MX & 3.5 & - & $4.13^{\mathrm{a}}$ & - \\
L-cystine & 0.18 & - & 0.18 & - \\
AIN-93-VX & 1 & - & $1.18^{\mathrm{a}}$ & - \\
Choline bitartrate & 0.25 & - & 0.25 & - \\
Tert-butylhydroquinone & 0.0008 & - & 0.0008 & - \\
\hline Total & 99.93 & 380 & 100.74 & 448 \\
\hline \% total energy & & & & \\
Carbohydrate & 75.8 & & 51.3 & \\
Fat & 9.5 & & 36.2 & \\
Protein & 14.7 & & 12.5 & \\
\hline
\end{tabular}

Source: [26,27]

$\mathrm{ND}=$ normal diet; HFFD $=$ high fat and fructose diet

${ }^{a}$ mineral mix and vitamin mix were adjusted to provide equal amounts of micronutrients per unit of energy, resulting in a $0,81 \%$ increase in the total weight of the HFFD (100.74 $\mathrm{g}$ instead of $99.93 \mathrm{~g}$ ).

\subsection{Insulin Resistance Induction by HFFD}

After three days of adaptation, the rats were randomly divided into six groups based on their fasting blood glucose. One group $(\mathrm{n}=4)$ were fed normal diet (AIN93M), whereas five groups ( $\mathrm{n}=4$ per group) were fed HFFD diet for 4 weeks. Table 1 shows the composition of normal diet (ND) and HFFD.

\subsection{Treatment Protocols}

Wistar rats were randomly divided into six groups, consisted of four rats for each group:

1. NLC (normal control); rats were given ND and distilled water by forced feeding for 10 weektreatments

2. NC (negative control); rats were given HFFD and distilled water by forced feeding for 10 weektreatments

3. PC (positive control); rats were given HFFD for 10 week-treatments and forced feeding of pioglitazone $1.35 \mathrm{mg} \mathrm{kg}^{-1}$ bw (body weight) for the last 6 weektreatments

4. LA (low AEPC); rats were given HFFD for 10 week-treatments and forced feeding of $6.25 \mathrm{mg}$ total anthocyanin $\mathrm{kg}^{-1}$ bw for the last 6 weektreatments

5. MA (medium AEPC); rats were given HFFD for 10 week-treatments and forced feeding of $12.5 \mathrm{mg}$ total anthocyanin $\mathrm{kg}^{-1}$ bw for the last 6 weektreatments

6. HA (high AEPC); rats were given HFFD for 10 week-treatments and forced feeding of $25 \mathrm{mg}$ total anthocyanin $\mathrm{kg}^{-1}$ bw for the last 6 week-treatments

Distilled water was prepared fresh daily as well as feed was changed every day.

\subsection{Plasma and Serum Collection and Tissue Samplings}

At the end of the experiments, the rats were fasted overnight $(12 \mathrm{~h})$ and then anesthetized using sodium pentobarbital. At the 0 th, 4 th, and 10 th week of experiment, blood samples were collected from retroorbital sinus of rats. The blood was collected into heparinised or non-heparinised tubes and centrifuged at $2000 \mathrm{rpm}$ for $20 \mathrm{~min}$, respectively. The plasma and serum were collected and stored at $-80^{\circ} \mathrm{C}$ until analysis to determine the biochemical parameters. The pancreases were removed, washed in ice-cold phosphate buffer saline

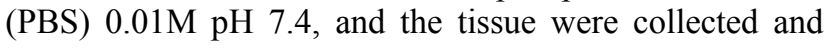
fixed in $10 \%$ formalin for histopathological analysis. For GLP1R analysis, after washing, pancreatic tissues were collected and kept at $-80^{\circ} \mathrm{C}$ until analysis.

\subsection{Serum Fasting Glucose, Insulin and HOMA Analysis}

Serum fasting glucose levels were determined at the 0 , 4th, and 10th week of the experiments using a GOD-PAP method. Serum insulin levels were determined at the 10th week of the experiments using an ELISA Kit (Elabscience, Wuhan, Hubei, China) according to the manufacturer's 
protocol. Homeostasis model assessments for insulin resistance (HOMA-IR) and HOMA- $\beta$ values were calculated by using the following formula [28]:

HOMA-IR $=\left[\right.$ fasting insulin $\left(\mathrm{mU} \mathrm{L}^{-1}\right) \times$ fasting glucose $(\mathrm{mmol} / \mathrm{L})] / 22.5$

HOMA $-\beta=\left[20 \mathrm{x}\right.$ fasting insulin $\left.\left(\mathrm{mU} \mathrm{L}^{-1}\right)\right] /[$ fasting glucose -3.5$]$

While HOMA-IS values were calculated using formula of Matsuda (1999) as follows:

HOMA-IS $=405 /\left(\right.$ fasting insulin $\left(\mathrm{IU} \mathrm{L} \mathrm{L}^{-1}\right) \times$ fasting glucose $\left.\left(\mathrm{mmol} \mathrm{L}^{-1}\right)\right)$

\subsection{Plasma GLP1 and Pancreatic GLP1R Analysis}

Plasma GLP1 and pancreatic GLP1R levels were determined by using an ELISA Kit (Elabscience, Wuhan, Hubei, China) according to the manufacturer's protocols.

\subsection{Histopathological Analysis of Pancreas}

Small pieces of pancreas were fixed with formalin $10 \%$ in PBS and embedded in paraffin. Section $(8 \mu \mathrm{m})$ were cut and stained with hematoxylin and eosin and observed under a microscope (Olympus BX-52 Microscope). Images were captured using a camera (Olympus DP-21 Camera) at a 400x magnification [29].

\subsection{Statistical Analysis}

The results are expressed as the means \pm standard deviation (SD). The statistical analysis data were based on a one-way ANOVA followed by Duncan's multiple range test (DMRT). Correlation between parameters were measured using Pearson correlation test. The data were analysed using the SPSS statistical package (IBM SPSS statistics, version 18.0).

\section{Results}

\subsection{Effect of AEPC on Fasting Serum Glucose}

The administration of AEPC affected the fasting serum glucose of rats as seen on Figure 1. At the beginning of research, all groups had the same value of fasting serum glucose, meant that all rats were randomly divided (Figure 1A). HFFD treatment made fasting serum glucose higher than AIN93 diet, which increases approximately $152 \%$ (Figure 1B). AEPC treatment for six weeks at medium dose lowered fasting serum glucose as much as pioglitazone groups, i.e. decreases approximately $40 \%$. Low and high dose of AEPC could also lower fasting serum glucose though not as much as medium dose (Figure 1C).

\subsection{Effect of AEPC on fasting serum insulin}

Fasting serum insulin of rats fed HFFD were not influenced by the administration of AEPC (Figure 2). As shown in Figure 2, after ten-week treatment, all groups with HFFD had the same fasting serum insulin, independent on treatment given to the groups. Fasting serum insulin of rats fed HFFD were higher than rats fed normal diet. Fasting serum insulin of pioglitazone and high dose of AEPC groups were the same as normal control groups.

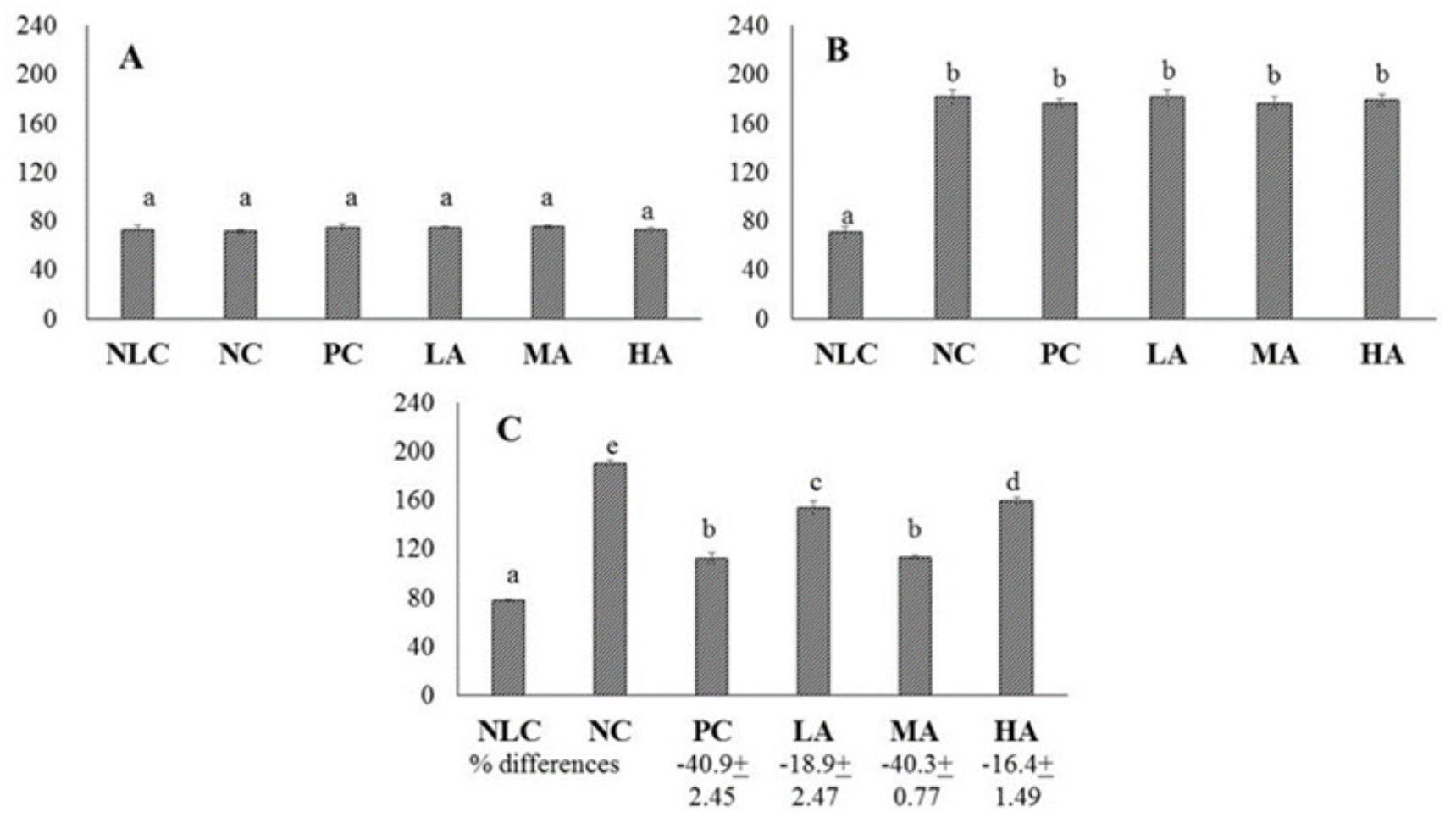

Figure 1. Effect of AEPC treatment on the fasting serum glucose $\left(\mathrm{mg} \mathrm{dL}^{-1}\right)$ of rats at week 0 (A), week 4 (B) and week $10(\mathrm{C})$. (NLC=normal control/normal diet; $\mathrm{NC}=$ negative control/HFFD; $\mathrm{PC}=$ positive control/ $\mathrm{HFFD}+$ pioglitazone $1.35 \mathrm{mg} \mathrm{kg}^{-1} \mathrm{bw}$; $\mathrm{LA}^{-} \mathrm{HFFD}+\mathrm{AEPC} 6.25 \mathrm{mg} \mathrm{kg}{ }^{-1} \mathrm{bw}$; $\mathrm{MA}=\mathrm{HFFD}+\mathrm{AEPC} 12.5 \mathrm{mg} \mathrm{kg}^{-1}$ bw.; HA=HFFD+ AEPC $25 \mathrm{mg} \mathrm{kg}^{-1}$ bw; $\mathrm{n}=4$; difference letter means difference value at $5 \%$ significance, $\%$ differences are compared to $\mathrm{NC}$ group) 


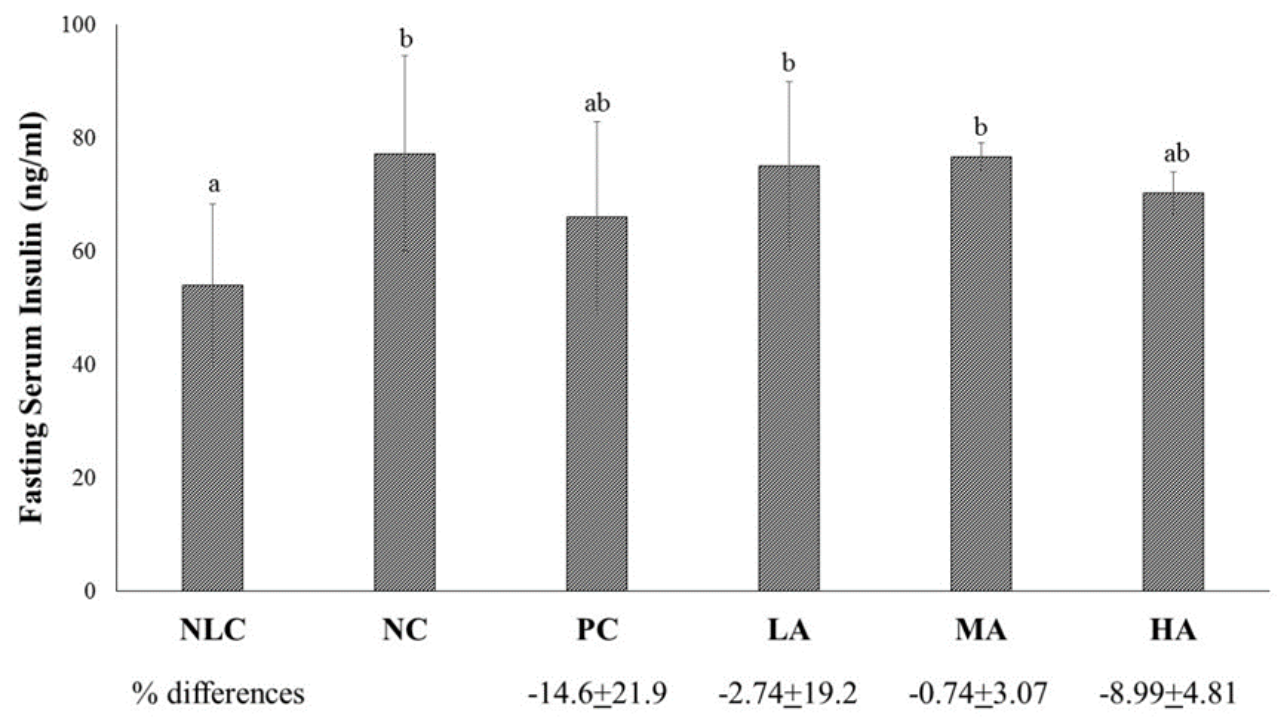

Figure 2. Effect of AEPC on the fasting serum insulin of rats after 10 weeks of treatment. See Figure 1 for further explanation

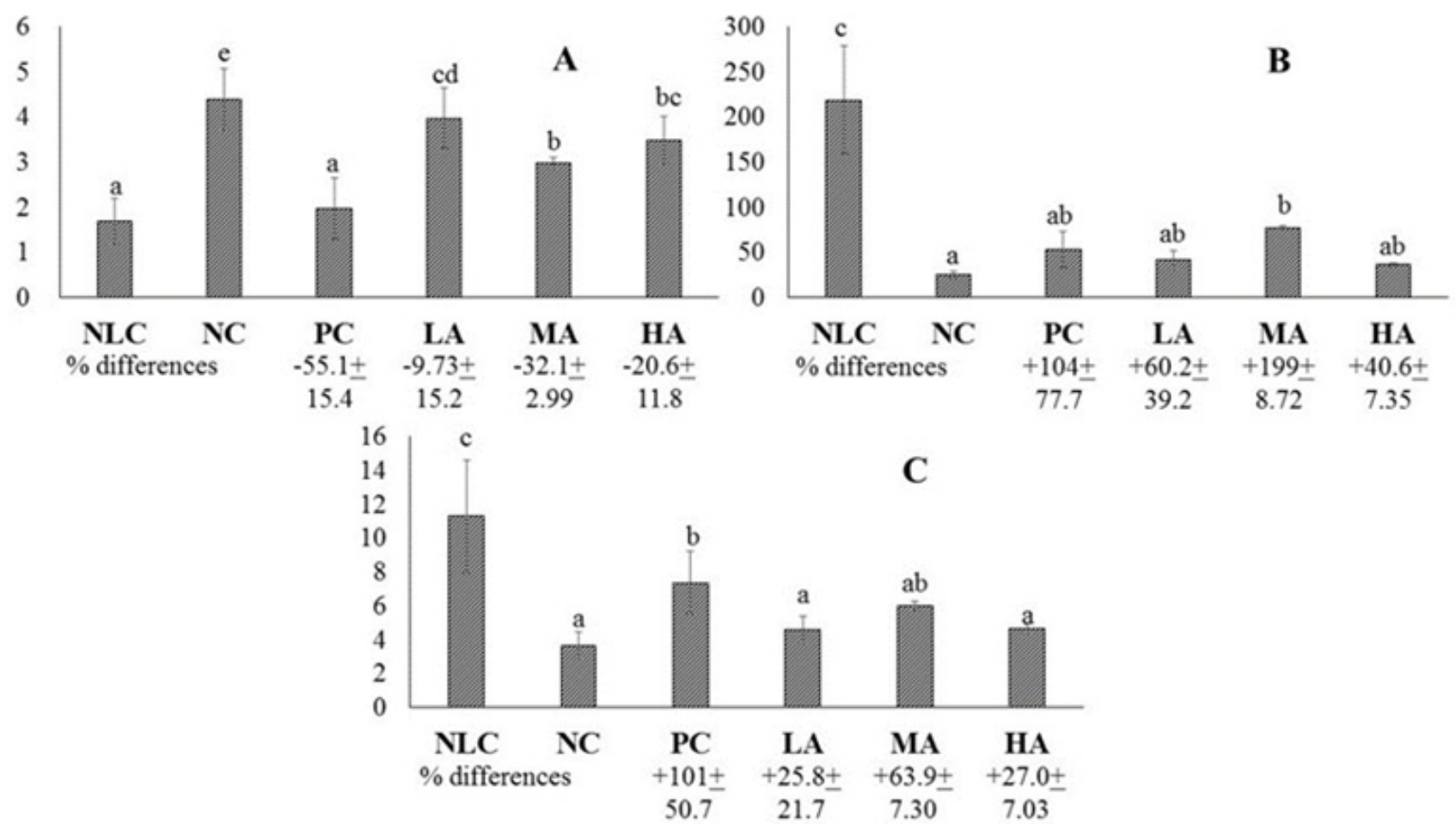

Figure 3. HOMA-IR (A), HOMA- $\beta$ (B), and HOMA-IS (C) scores after 10 week-treatment of rats with or without AEPC. See Figure 1 for further explanation

\subsection{Effect of AEPC on HOMA-IR, HOMA- $\beta$, and HOMA-IS Scores}

The administration of AEPC decreased HOMA-IR, while it was increased in HOMA- $\beta$ and HOMA-IS of rats fed HFFD (Figure 3). Figure 3 showed HOMA-IR scores after 10 week-treatment of rats with or without AEPC. After 10 week-treatment, rats of normal and positive control groups had the lowest HOMA-IR score, while negative control group had the highest one. AEPC treatments could improve HOMA-IR, the best condition was by giving AEPC of $25 \mathrm{mg} \mathrm{kg}^{-1}$ bw, which could decrease in $32 \%$ of HOMA-IR score (Figure $3 \mathrm{~A}$ ).

High fat and fructose diet decreased level of pancreatic beta-cell function. Pioglitazone and AEPC treatments at low and high doses were not enough to increase in
HOMA- $\beta$ score, while AEPC treatment at medium dose improved pancreatic beta-cell function with $200 \%$ increase of HOMA- $\beta$ score (Figure 3B). HOMA-IS decreased after feeding of HFFD for 10 weeks, meaning that insulin sensitivity of rats fed HFFD was decreased. AEPC treatment at low and high doses could not improve insulin sensitivity, while pioglitazone and AEPC treatments at medium dose could increase $100 \%$ and $64 \%$ HOMA-IS scores, respectively (Figure 3C).

\subsection{Effect of AEPC on Plasma GLP1 and Pancreatic GLP1R}

The administration of AEPC to rats fed HFFD improved plasma GLP1 and pancreatic GLP1R (Figure 4). High fat and fructose diet lowered plasma GLP1 level as 
seen in Figure 4A. Treatments with pioglitazone and medium and high doses of AEPC increased plasma GLP1 level by 70,52 , and $42 \%$, respectively. It meant that AEPC could improve plasma GLP1 of rats fed HFFD. HFFD reduced pancreatic GLP1R level (Figure 4B). Treatment with pioglitazone and low and medium doses of AEPC increased pancreatic GLP1R levels by 44, 38, and $31 \%$, respectively. It meant that AEPC could improve sensitivity of pancreatic GLP1R of rats fed HFFD.

\subsection{Correlation between HOMA-IR and Other Parameters}

Correlation between HOMA-IR score at 10 week-treatment and other parameters were seen in Table 2. HOMA-IR as an indicator of insulin resistance had strong positive correlation with fasting serum glucose, and fasting serum insulin, and strong negative correlation with HOMA- $\beta$ score, HOMA-IS score, plasma GLP1, and pancreatic GLP1R levels. The higher the fasting serum glucose and fasting serum insulin, the higher insulin resistance incident, while the higher the HOMA- $\beta$ and HOMA-IS score, GLP1 plasma, and pancreatic GLP1R level, the lower insulin resistance incident.

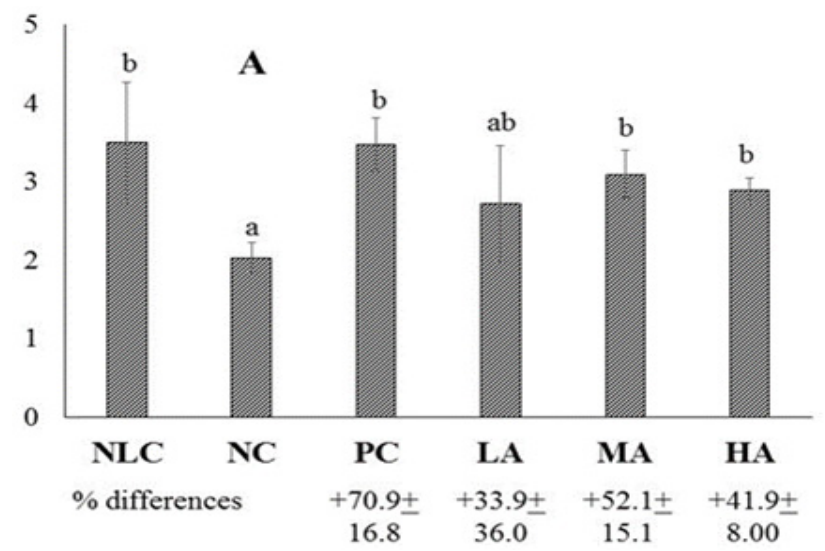

Table 2. Correlation between HOMA-IR Score and Other Parameters

\begin{tabular}{ll}
\hline Parameters & Pearson's Correlation Score with HOMA-IR \\
\hline Fasting serum glucose & $0.825^{* *}$ \\
Fasting serum insulin & $0.661^{* *}$ \\
HOMA- $\beta$ & $-0.534^{* *}$ \\
HOMA-IS & $-0.830^{* *}$ \\
Plasma GLP-1 & $-0.740^{* *}$ \\
Pancreatic GLP-1R & $-0.508^{*}$ \\
\hline
\end{tabular}

**means that there is a correlation at $1 \%$ significant. *means that there is a correlation at $5 \%$ significant.

\subsection{Pancreatic Histopathological Analysis}

Figure 5 shows pancreatic morphology of rats after treatment with or without AEPC to rats fed HFFD. Negative control group (NC) showed presence of necrosis with lymphocyte and neutrophil infiltration, while the other four treatment groups (PC, LA, MA, and HA) showed there was no change in pancreatic histopathologic features. This suggested that pioglitazone and all of three doses of AEPC were capable of providing repair of pancreatic cell damage caused by HFFD. The effect of all three doses of AEPC on pancreatic tissue repair damaged by HFFD was proportional to pioglitazone (Figure 5).

Figure 4. Plasma GLP1, ng mL $\mathrm{mL}^{-1}$ (A) and pancreatic GLP1R, ng g ${ }^{-1}$ (B) of rats with or without AEPC after 10 weeks of treatment. See Figure 1 for further explanation
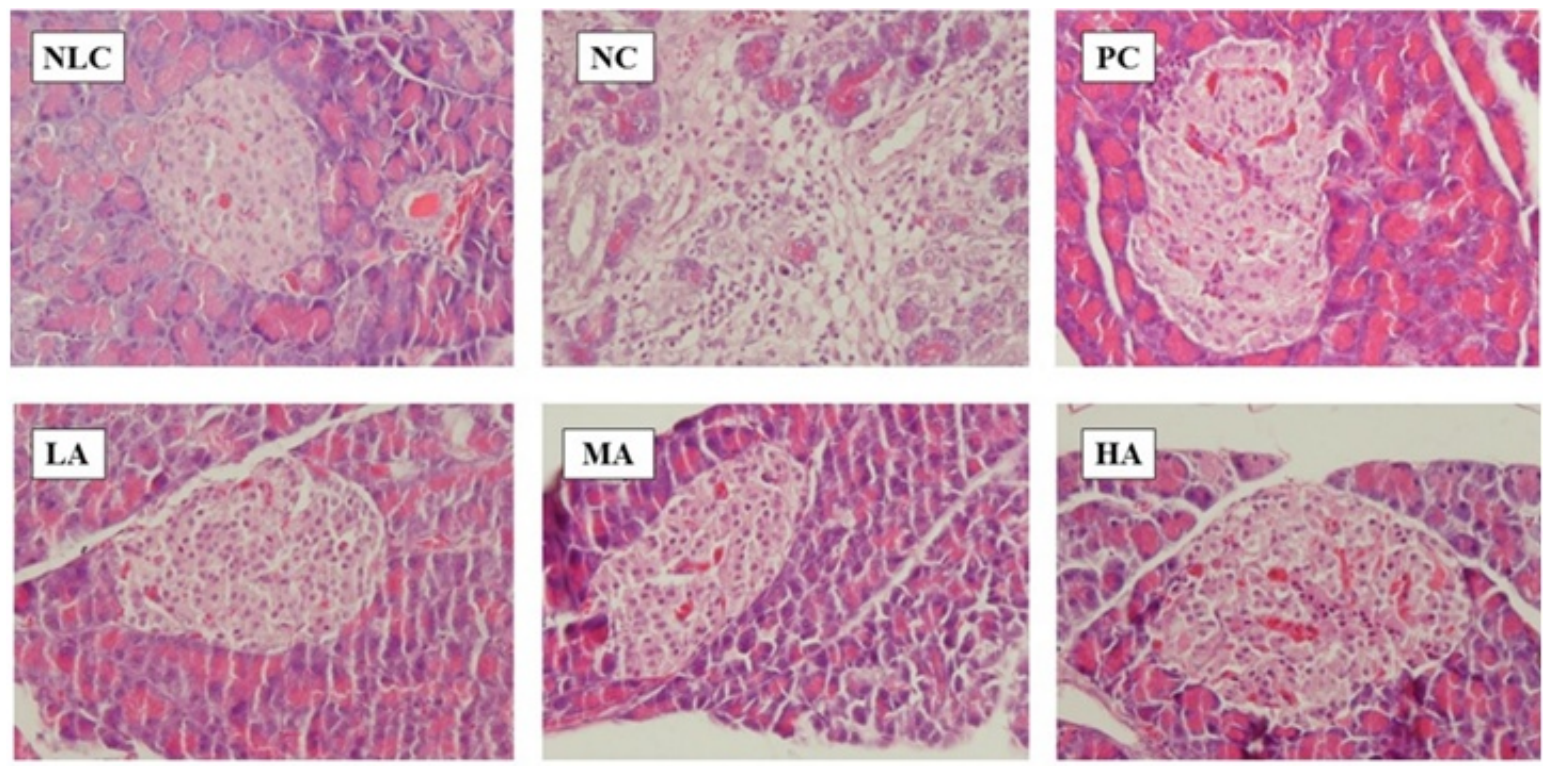

Figure 5. Histopathology of pancreatic islet $(\mathrm{NLC}=$ normal control/normal diet; $\mathrm{NC}=$ negative control/HFFD; $\mathrm{PC}=$ positive control/ $\mathrm{HFFD}+$ pioglitazone $1.35 \mathrm{mg} \mathrm{kg}^{-1}$ bw.; LA=HFFD + AEPC $6.25 \mathrm{mg} \mathrm{kg}^{-1}$ bw; MA=HFFD + AEPC $12.5 \mathrm{mg} \mathrm{kg}^{-1} \mathrm{bw}$; HA=HFFD + AEPC $\left.25 \mathrm{mg} \mathrm{kg}{ }^{-1} \mathrm{bw}\right)$ 


\section{Discussion}

The blood glucose levels between groups at the beginning of the study (week 0) were homogeneous. Therefore, it could be interpreted that the rats had been randomly divided into groups based on their blood glucose levels. Administration of HFFD caused an increase in blood glucose levels compared to rats fed standard AIN93M (week 4). The increase in blood glucose levels was very significant which indicated that the provision of HFFD made blood glucose levels higher. This result is in line with other studies that overconsumption in fat and fructose lead to blood glucose increase [30,31,32]. At the end of the 10th week in which the treatment was completed, normal group blood glucose levels had the lowest blood glucose levels. Administration of HFFD without other treatment (negative control group) had the highest blood glucose levels. Standard drug administration of pioglitazone (positive control group) caused blood glucose levels to approach the normal group. Similarly, treatment of AEPC $12.5 \mathrm{mg} \mathrm{kg}^{-1}$ bw produced the same blood glucose levels as standard drug administration. It meant that high blood glucose level caused by HFFD could be normalized by AEPC. While AEPC of 6 and $25 \mathrm{mg} \mathrm{kg}^{-1}$ bw of rats also caused blood glucose levels to decreased compared to the negative control group, but the decrease was not as high as AEPC $12.5 \mathrm{mg}$ of rat. This result was similar to previously research, which showed that purple corn decreased blood glucose level in mice fed high fat diet [33].

At the end of week 10, insulin level of rats fed HFFD were higher than normal control. This result was the same as some researches, who stated that insulin concentrations were higher in the rats fed high fat diet compared to control [34-39], although their results were slightly different. Le et al said that high fructose diet in offspring of type 2 diabetic patients increased fasting plasma concentration of insulin [40]. Tsuda et al. also got the same result that consumption of purple corn color containing cyanidin-3-glucoside, which decreased insulin level of mice fed high fat diet [33]. AEPC feeding prevented the increase in serum insulin caused by HFFD consumption. The lower insulin levels were achieved by the group with a dose of AEPC $25 \mathrm{mg} \mathrm{kg}^{-1}$ bw (Figure 2). A study in human showed that ones who have insulin resistance will release insulin fourfold to fivefold higher than insulin-sensitive individuals [41]. Xu et al. said that at the first phase insulin-resistant state, in a respond to glucose load, there is a loss of initial insulin secretion, resulting in postprandial hyperglycemia. Afterwards, hyperinsulinemia is happened because of an excessive insulin response in the second phase insulin-resistant state. Subsequently, insulin resistance become worse and also pancreatic $\beta$-cell become dysfunction [42].

The HOMA-IR is well-defined biomarker for the assessment of insulin resistance [43]. Feeding of HFFD increased insulin resistance, while pioglitazone improved it. AEPC feeding also ameliorated insulin resistance although their HOMA-IR scores were still higher than pioglitazone group. Medium dose of AEPC was better than low and high dose of AEPC in improvement of insulin resistance (Figure 3).

From Figure 3, it can be seen that the best HOMA- $\beta$ score was shown by the group receiving an AEPC at a dose of $12.5 \mathrm{mg} \mathrm{kg}^{-1}$ bw , approaching the positive control, although this level was still lower than the normal control. A low-dose AEPC resulted in a lower HOMA- $\beta$ level. This indicated that this AEPC dose were not been able to repair the damage of pancreatic $\beta$ cells. The highest dose of AEPC also showed a low HOMA- $\beta$ score, probably because the dose actually served as a pro-oxidant.

It is reported that GLP-1 action is deficient in subjects with type 2 diabetes mellitus [44]. GLP-1 is a protective cytokine against inflammatory events, which in this study is caused by oxidative stress due to the HFFD diet. The presence of GLP-1 inhibits various pro-inflammatory cytokines that trigger insulin resistance conditions. The higher the level of GLP-1 content, the protective effect is more prominent. HFFD diet (negative control) causes the lowest GLP-1 levels, whereas positive controls show higher GLP-1 levels. Giving AEPC for all doses can increase plasma GLP-1 levels. This shows the protective nature of AEPC in preventing damage, which caused by HFFD administration, starting from a dose of $6.25 \mathrm{mg} \mathrm{kg}^{-1} \mathrm{bw}$.

In line with GLP1, pancreatic GLP1R as a receptor of GLP1 in pancreas, also have a negative correlation with insulin resistance. GLP1 activate the expression of GLP1R on beta cells and therefore trigger glucose-induced insulin secretion. Furthermore, GLP1 inhibit glucagon secretion from pancreatic alpha cells [45].

Based on Table 2, then the next discussion was done by using the HOMA-IR score as a reference to know the relationship between all other parameters. This HOMA-IR score was chosen because it correlates strongly with insulin tolerance test (ITT), so it can be used as a predictor for insulin resistance conditions in Wistar rats. HOMA-IR can detect insulin resistance with $90 \%$ sensitivity. Compared with other methods for assessing insulin resistance, HOMA-IR has advantages in terms of ease of testing, stressing fewer test animals, and avoiding the risk of hypoglycemia in test subjects [46].

Administration of HFFD increases serum blood glucose and insulin levels, as well as HOMA-IR. HOMA-IR scores correlated positively with blood glucose and serum insulin levels. This result is in line with previous study, where high-fat dietary administration led to significant increases in serum glucose and insulin levels compared with normal control [47]. High fat and fructose diets cause an increase of free fatty acid and glucose blood level, resulting in insulin resistance that stimulates lipolysis and insulin secretion. The compensatory responses of insulin resistance include adipogenesis which can lead to diabetes [48].

This study has shown that AEPC administration was able to suppress blood glucose and serum insulin level compared to high fat and fructose diet group. The best suppression of blood glucose levels was obtained in the group with an AEPC dose of $12.5 \mathrm{mg} \mathrm{kg}^{-1} \mathrm{bw}$, while the lowest serum insulin at AEPC was $25 \mathrm{mg} \mathrm{kg}^{-1} \mathrm{bw}$.

There was a negative correlation between HOMA-IR and plasma GLP1 levels, which indicates that the lower plasma GLP1 levels, the higher the incidence of insulin resistance. GLP1 is a hormone produced by the gastrointestinal tract and stimulates insulin secretion due to elevated blood glucose level. Aulinger et al. found that GLP1 levels were correlated with the incidence of insulin resistance in healthy subjects [49]. One mechanism proposed why GLP1 improve insulin resistance is that 
GLP1 improve $\beta$-cell function, reduce gluconeogenesis, and improve insulin sensitivity [50].

In patients with type 2 diabetes mellitus and insulin resistance, there was a decrease in GLP1 levels. It is known that insulin resistance is associated with a chronic inflammatory process in fatty tissue, one of which is caused by tissue oxidative stress due to HFFD administration. The accumulated macrophages in fatty tissue secrete various pro-inflammatory cytokines, resulting in an inflammatory reaction. GLP1 is able to inhibit macrophage infiltration in fat, heart, and liver tissue, thus plays an important role in inhibiting the secretion of these pro-inflammatory cytokines [51]. Thus, in conditions of insulin resistance (high HOMA-IR), low levels of GLP1 will be found. AEPC also improve GLP1R levels, means that there is an improvement in beta cells condition.

\section{Conclusions}

The results of the study showed that AEPC administration improved insulin resistance, pancreatic- $\beta$ cells, and hepatic sensitivity to insulin, reduced blood glucose levels, increased plasma GLP1 levels, pancreatic GLP1R level and improved pancreatic histopathology. HOMA-IR scores positively correlated with blood glucose levels and blood insulin levels, but negatively correlated with HOMA- $\beta$ and HOMA-IS scores. The condition of insulin resistance was negatively correlated with plasma GLP1 and pancreatic GLP1R. This result, indicated that the improvement of insulin resistance due to AEPC administration via improved plasma GLP1 and pancreatic GLP1R mechanism. Giving AEPC of $12.5 \mathrm{mg} \mathrm{kg}^{-1}$ bw yielding the best conditions approaching standard drug administration pioglitazone $1.35 \mathrm{mg} \mathrm{kg}^{-1}$ bw.

\section{Funding}

The research was funded by Coaching Research of Medical Science and Technology of Indonesian Ministry of Health (Riset Pembinaan Ilmu Pengetahuan dan Teknologi Kedokteran-RISBIN IPTEKDOK- Departemen Kesehatan Republik Indonesia) 2016 and Indonesian Ministry of Research, Technology and Higher Education through Beasiswa Pendidikan Pascasarjana Dalam Negeri (BPPDN).

\section{Acknowledgements}

We would like to acknowledge Dr. Arifin Noor Sugiharto for donating purple corn seed used in this study and Dr. Sugiyono for capturing the images of pancreatic morphology.

\section{Statement of Competing Interests}

The authors have no competing interests.

\section{List of Abbreviations}

AEPC anthocyanin extract of purple corn ANOVA analysis of variance

\begin{tabular}{|c|c|}
\hline bw & body weight \\
\hline DMRT & Duncan's multiple range test \\
\hline GLP1 & glucagon-like peptide 1 \\
\hline GLP1R & glucagon-like peptide 1 receptor \\
\hline HA & high AEPC group \\
\hline HFFD & high fat and fructose diet \\
\hline HOMA- $\beta$ & $\begin{array}{l}\text { homeostasis model assessments for } \beta \text {-cell } \\
\text { function }\end{array}$ \\
\hline OMA-IR & $\begin{array}{l}\text { homeostasis model assessments for insulin } \\
\text { resistance }\end{array}$ \\
\hline OMA-IS & $\begin{array}{l}\text { homeostasis model assessments for insulin } \\
\text { sensitivity }\end{array}$ \\
\hline LA & low AEPC group \\
\hline$A$ & medium AEPC group \\
\hline 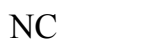 & negative control group \\
\hline $\mathrm{D}$ & normal diet \\
\hline LC & normal control group \\
\hline & phosphate buffer saline \\
\hline & positive control group \\
\hline & standard deviation \\
\hline
\end{tabular}

\section{References}

[1] World Health Organization. 2014. Global status report on noncommunicable diseases 2014. World Health Organization Press, Switzerland

[2] Indonesian Ministry of Health. 2018. Hasil Utama Riskesdas 2018 Health Research and Development Agency.

[3] Gutierrez-Rodelo, C., Roura-Gubierna, A., Olivares-Reyes, J.A. "Molecular mechanism of insulin resistance: an-update". Gaceta Medica De Mexico. 153, 197-209, 2017.

[4] Han, J., Yang, N., Zhang, F., Zhang, C., Liang, F., Xie, W., et al. "Rhizoma Anemarrhenae extract ameliorates hyperglycemia and insulin resistance via AMP-activated protein kinase in diabetic rodents". J Ethnopharmacol. 172, 368-376, 2015.

[5] Akagiri, S., Naito, Y., Ichikawa, H., Mizushima, K., Takagi, T. "A Model Mouse of Metabolic Syndrome; Increase in Visceral Adipose Tissue Precedes the Development of Fatty Liver and Insulin Resistance in High-Fat Diet-Fed Male KK / Ta Mice". J Clin Biochem Nutr. 42(March), 150-157, 2008

[6] Charradi, K., Elkahoui, S., Limam, F., Aouani, E. "High-fat diet induced an oxidative stress in white adipose tissue and disturbed plasma transition metals in rat: prevention by grape seed and skin extract". J Physiol Sci. 63(6), 445-455, 2013.

[7] Ming, M., Guanhua, L., Zhanhai, Y., Guang, C., Xuan, Z. "Effect of the Lycium barbarum polysaccharides administration on blood lipid metabolism and oxidative stress of mice fed high-fat diet in vivo". Food Chem. 113(4), 872-877, 2009.

[8] Noeman, S.A., Hamooda, H.E., Baalash, A.A. "Biochemical study of oxidative stress markers in the liver, kidney and heart of high fat diet induced obesity in rats". Diabetol Metab Syndr. 3(1), 17, 2011

[9] Liu, Y., Song, A., Zang, S., Wang, C., Song, G., Li, X., et al. "Jinlida reduces insulin resistance and ameliorates liver oxidative stress in high-fat fed rats". J Ethnopharmacol. 162, 244-252, 2015

[10] Lee, C.Y. "Quercetin / adenosine combination may induce insulin resistance in high fat diet-fed mice". Obes Res Clin Pract. 6(1), e85-90, 2012.

[11] Nagai, Y., Yonemitsu, S., Erion, D.M., Iwasaki, T., Stark, R., Weismann, D., et al. "The Role of Peroxisome ProliferatorActivated Receptor g Coactivator-1 b in the Pathogenesis of Fructose-Induced Insulin Resistance”. Cell Metab. 9, 252-264, 2009.

[12] Tran, L.T., Yuen, V.G., McNeil, J.H. "The fructose-fed rat: A review on the mechanisms of fructose-induced insulin resistance and hypertension”. Mol Cell Biochem. 332, 145-159, 2009.

[13] Bray, G.A., Nielsen, S.J., Popkin, B.M. "Consumption of highfructose corn syrup in beverages may play a role in the epidemic of obesity". Am J Clin Nutr. 79, 537-543, 2004.

[14] Vikrant, V., Grover, J.K., Tandon, N., Rathi, S.S., Gupta, N. "Treatment with extracts of Momordica charantia and Eugenia 
jambolana prevents hyperglycemia and hyperinsulinemia in fructose fed rats". J Ethnopharmacol. 76(2), 139-143, 2001.

[15] Suwannaphet, W., Meeprom, A., Yibchok-anun, S., Adisakwattana, S. "Preventive effect of grape seed extract against high-fructose diet-induced insulin resistance and oxidative stress in rats". Food Chem Toxicol. 48(7), 1853-1857, 2010.

[16] Jing, P. Purple corn anthocyanins: chemical structure, chemoprotective activity and structure / function relationships. Doctoral dissertation, The Ohio State University, Columbus, $\mathrm{OH}$, 2006.

[17] Long, N., Suzuki, S., Sato, S., Naiki-Ito, A., Sakatani, K., Shirai, T., et al. "Purple corn color inhibition of prostate carcinogenesis by targeting cell growth pathways". Cancer Sci. 104(3), 298-303, 2013.

[18] Ramos-Escudero, F., Muñoz, A.M., Alvarado-Ortíz, C., Alvarado, Á., Yáñez, J.A. "Purple corn (Zea mays L.) phenolic compounds profile and its assessment as an agent against oxidative stress in isolated mouse organs". J Med Food. 15(2), 206-215, 2012.

[19] Fukamachi, K., Imada, T., Ohshima, Y., Xu, J., Tsuda, H. "Purple corn color suppresses Ras protein level and inhibits 7,12 dimethylbenz[a]anthracene-induced mammary carcinogenesis in the rat". Cancer Sci. 99(9), 1841-1846, 2008.

[20] Li, J., Lim, S.S., Lee, J.-Y., Kim, J.-K., Kang, S.-W., Kim, J.-L., et al. "Purple corn anthocyanins dampened high-glucose-induced mesangial fibrosis and inflammation: possible renoprotective role in diabetic nephropathy". J Nutr Biochem. 23(4), 320-331, 2012.

[21] Akkarachiyasit, S., Charoenlertkul, P., Yibchok-anun, S., Adisakwattana, S. "Inhibitory activities of cyanidin and its glycoside and synergistic effect with acarbose against intestinal $\alpha$-glucosidase and pancreatic- $\alpha$-amylase". Int. J. Mol. Sci. 11, 3387-3396, 2010.

[22] Akkarachiyasit, S., Yibchok-anun, S., Wacharasindhu, S. Adisakwattana, S. "In vitro inhibitory effects of cyanidin-3rutinoside on pancreatic- $\alpha$-amylase and its combined effect with acarbose". Molecules. 16, 2075-2083, 2011.

[23] Casedas, G., Les, F., Gonzales-Burgos, E., Gomez-Serranillos, M.P., Smith, C., Lopez, V. "Cyanidin-3-O-glucosidase inhibits different enzymes involved in central nervous system pathologies and type-2 diabetes". South African Journal of Botany. 120, 241-246, 2019.

[24] Choi, K., Choi, S.I., Park, M.H., Han, J.S. "Cyanidin-3-O-glucoside ameliorates postprandial hyperglycemia in diabetic mice". Journal of Life Science. 27(1), 32-37, 2017

[25] Sui, X., Zhang, Y., Zhou, W. "In vitro and in silico studies of the inhibition activity of anthocyanins against porcine pancreatic- $\alpha$ amylase". Journal of Functional Foods. 2016, 21, 50-57.

[26] Choi, W.H., Um, M.Y., Ahn, J., Jung, C.H., Ha, T.Y. "Long-term intake of rice improves insulin sensitivity in mice fed a high-fat diet". Nutrition. 30(7-8), 920-927, 2014.

[27] Flanagan, A.M., Brown, J.L., Santiago, C.A., Aad, P.Y., Spicer, L.J., Spicer, M.T. "High-fat diets promote insulin resistance through cytokine gene expression in growing female rats". J Nutr Biochem. 19(8), 505-513, 2008.

[28] Matthews, D.R., Hosker, J.P., Rudenski, A.S., Naylor, B.A., Treacher, D.F., Turner, R.C. "Homeaostasis model assessment: insulin resistance and beta-cell function from fasting plasma glucose and insulin concentrations in man". Diabetologia. 28(7), 412-419, 1985.

[29] Takikawa, M., Inoue, S., Horio, F., Tsuda, T. "Dietary anthocyanin-rich bilberry extract ameliorates hyperglycemia and insulin sensitivity via activation of AMP-activated protein kinase in diabetic mice". J Nutr. 140, 527-533, 2010.

[30] De Oliveira Sá, G., dos Santos Neves, V., de Oliveira Fraga, S.R. Souza-Mello, V., Barbosa-da-Silva, S. "High-intensity interval training has beneficial effects on cardiac remodeling through local renin-angiotensin system modulation in mice fed high-fat or highfructose diets". Life Sci. 189, 8-17, 2017.

[31] Nasri, R., Abdelhedi, O., Jemil, I., Daoued, I., Hamden, K., Kallel, C., et al. "Ameliorating effects of goby fish protein hydrolysates on high-fat-high-fructose diet-induced hyperglycemia, oxidative stress and deterioration of kidney function in rats". Chem Biol Interact. 242, 71-80, 2015.

[32] Wang, J, Hu, X., Ai, W., Zhang, F., Yang, K., Wang, L., et al. "Phytol increases adipocyte number and glucose tolerance through activation of PI3K / Akt signaling pathway in mice fed high-fat and high-fructose diet”. Biochem Biophys Res Commun. 489(4), 432-438, 2017.

[33] Tsuda, T., Horio, F., Uchida, K., Aoki, H., Osawa, T. "Dietary Cyanidin 3-O- $\beta$-D-Glucoside-Rich Purple Corn Color Prevents Obesity and Ameliorates Hyperglycemia in Mice". J Nutr. 133, 2125-2130, 2003

[34] Ambika, S., Saravanan, R. "Effect of bergenin on hepatic glucose metabolism and insulin signaling in C57BL / 6J mice with high fat-diet induced type 2 diabetes". J Appl Biomed. 14(3), 221-227, 2016.

[35] Choi, W.H., Ahn, J., Jung, C.H., Seo, J.S., Ha, T.Y. "Korean diet prevents obesity and ameliorates insulin resistance in mice fed a high-fat diet". J Ethn Foods. 4(1), 36-43, 2017.

[36] Cremonini, E., Bettaieb, A., Haj, F.G., Fraga, C.G., Oteiza, P.I. “()-Epicatechin improves insulin sensitivity in high fat diet-fed mice". Arch Biochem Biophys. 599, 13-21, 2016.

[37] Xu, J., Cao, K., Feng, Z., Liu, J. "Benefits of the soluble and insoluble fractions of bitter gourd in mice fed a high-fat diet". J Funct Foods. 42, 216-223, 2018

[38] Yook, J., Kim, K., Park, J.E., Lee, S., Cha, Y. "Microalgal Oil Supplementation Has an Anti-Obesity Effect in C57BL / 6J Mice Fed a High Fat Diet”. Prev Nutr Food Sci. 20(4), 230-237, 2015.

[39] Yoshioka, H., Mizuno, Y., Yamaguchi, T., Ichimaru, Y., Takeya, K. "Methyl dehydroabietate counters high fat diet-induced insulin resistance and hepatic steatosis by modulating peroxisome proliferator-activated receptor signaling in mice". Biomed Pharmacother. 99, 214-219, 2018

[40] Le, K.A., Ith, M., Kreis, R., Faeh, D., Bortolotti, M., Tran, C., Boesch, C., Tappy, L. "Fructose overconsumption causes dyslipidemia and ectopic lipid deposition in healthy subjects with and without a family history of type 2 diabetes". Am J Clin Nutr, 89, 1760-1765, 2009.

[41] Kahn, S.E., Hull, R.L., Utzschneider, K.M. "Mechanisms linking obesity to insulin resistance and type 2 diabetes". Nature., 444 , 840-846, 2006.

[42] Xu, H., Li, X., Adams, H., Kubena, K., Guo, S. "Etiology of Metabolic Syndrome and Dietary Intervention". Int. J. Mol. Sci., 20, 128, 2019.

[43] Borai, A., Livingstone, C., Kaddam, I., Ferns, G. "Selection of the appropriate method for the assessment of insulin resistance". $B M C$ Med Res Methodol. 11, 158, 2011.

[44] Rizzo, M., Nikolic, D., Maria, A., Mannina, C., Montalto, G., McAdams, B.S., et al. "GLP-1 receptor agonists and reduction of cardiometabolic risk : Potential underlying mechanisms". Biochim Biophys Acta Mol Basis Dis. 1864, 2814-2821, 2018.

[45] Ørgaard, A., Holst, J.J. "The role of somatostatin in GLP-1-induced inhibition of glucagon secretion in mice". Diabetologia. 60(9), 1731-1739, 2017.

[46] Antunes, L.C., Elkfury, J.L., Jornada, M.N., Foletto, K.C., Bertoluci, M.C. "Validation of HOMA-IR in a model of insulinresistance induced by a high-fat diet in Wistar rats". Arch Endocrinol Metab. 60, 2, 138-142, 2016.

[47] El-sayed, M., Ghareeb, D., Talat, H.A., Sarhan, E.M. "High fat diet induced insulin resistance and elevated retinol binding protein 4 in female rats, treatment and protection with Berberís vulgaris extract and vitamin A". Pak J Pharm Sci. 26, 1189-1196, 2009.

[48] Abd-Allah, A.B., Megahed, A.A.Y., Gomaa, R.S., Hussein, S.F.E. "Effect of moderate intensity exercise on serum visfatin level in male rat model of obesity". AAMJ. 10, 20-42, 2013.

[49] Aulinger, B.A., Vahl, T.P., Wilson-Pérez, H.E., Prigeon, R.L., D'Alessio, D.A. " $\beta$-cell sensitivity to GLP-1 in healthy humans is variable and proportional to insulin sensitivity". J Clin Endocrinol Metab. 100, 2489-2496, 2015.

[50] Lee, Y., Shin, S., Shigihara, T., Hahm, E., Liu, M., Han, J., et al. "Glucagon-Like Peptide-1 gene therapy in obese diabetic mice results in Long-Term Cure of Diabetes by Improving Insulin Sensitivity and Reducing Hepatic Gluconeogenesis". Diabetes. 56, 1671-1679, 2007.

[51] Guo, C., Huang, T., Chen, A., Chen, X., Wang, L., Shen, F., et al. "Glucagon-like peptide 1 improves insulin resistance in vitro through anti-inflammation of macrophages". Brazilian J Med Biol Res. 49, 1-9, 2016. 